\title{
Docetaxel-carboplatin in combination with erlotinib and/or bevacizumab in patients with non-small cell lung cancer
}

\section{Eftimia Boutsikou' \\ Theodoros Kontakiotis' \\ Paul Zarogoulidis' \\ Kaid Darwiche ${ }^{2}$ \\ Ellada Eleptheriadou' \\ Konstantinos Porpodis' \\ Grammati Galaktidou ${ }^{3}$ \\ Leonidas Sakkas ${ }^{4}$ \\ Wolfgang Hohenforst- \\ Schmidt ${ }^{5}$ \\ Kosmas Tsakiridis ${ }^{6}$ \\ Theodoros Karaiskos ${ }^{7}$ \\ Konstantinos Zarogoulidis'}

'Pulmonary Department-Oncology

Unit, G Papanikolaou General

Hospital, Aristotle University of

Thessaloniki, Greece; ${ }^{2}$ University

Pulmonary Department-Interventional

Unit, Ruhrland Klinic, University

of Duisburg-Essen, Essen, Germany;

${ }^{3}$ Theagenio Anticancer Institute Research Laboratory, ${ }^{4}$ Department of Pathology, G Papanikolaou Hospital, Thessaloniki, Greece; ${ }^{5}$ I Medical Clinic, Hospital Coburg, University of Wuerzburg, Coburg, Germany;

${ }^{6}$ Cardiothoracic Surgery Department, Saint Luke Private Hospital, Panorama, ${ }^{7}$ Cardiothoracic Surgery Department, G Papanikolaou General Hospital, Aristotle University of Thessaloniki, Thessaloniki, Greece

Correspondence: Paul Zarogoulidis Pulmonary Department-Oncology Unit, G Papanikolaou General Hospital, Aristotle University of Thessaloniki, Thessaloniki, Greece

$\mathrm{Tel}+3023$ I 77271974

Fax +30 23I 0992433

Email pzarog@hotmail.com
This article was published in the following Dove Press journal:

OncoTargets and Therapy

28 February 2013

Number of times this article has been viewed

Background: Bevacizumab and erlotinib have been demonstrated to prolong overall survival in patients with non-squamous non-small cell lung cancer (NSCLC). We designed a four-arm Phase III trial to evaluate the efficacy and toxicity of the combination of docetaxel, carboplatin, bevacizumab, and erlotinib in the first-line treatment of patients with NSCLC.

Methods: A total of 229 patients with stage IIIb/IV non-squamous NSCLC were treated with two cycles of carboplatin (area under the concentration-time curve 5.5) and docetaxel $100 \mathrm{mg} / \mathrm{m}^{2}$ as chemotherapy. After completion of two treatment cycles, patients were evaluated for response and divided into four groups: 61/229 continued with four more cycles of chemotherapy (control group), 52/229 received chemotherapy plus erlotinib $150 \mathrm{mg}$ daily, $56 / 229$ received chemotherapy plus bevacizumab $7.5 \mathrm{mg} / \mathrm{kg}$, and $60 / 229$ were treated with the combination of chemotherapy, erlotinib, and bevacizumab until disease progression. The primary endpoint was overall survival.

Results: Over 4 years of follow-up, there was no statistically significant difference in survival and time to progression between the four treatment groups. After two cycles of chemotherapy, responders and nonresponders were divided according to their response in order to examine the role of initial response as an independent factor in survival and response when a biological agent is combined with chemotherapy. Nonresponders, who received additional therapy with bevacizumab or combination therapy, had a survival benefit [657 days ( $95 \%$ confidence interval 349-970) and 681 days (95\% confidence interval 315-912), respectively], which was statistically significant compared with continuation of cytotoxic chemotherapy $(P<0.001)$. The combination therapy had a safety profile comparable with that of bevacizumab and erlotinib taken individually.

Conclusion: Administration of bevacizumab and erlotinib in combination with first-line chemotherapy, followed by bevacizumab and erlotinib monotherapy as maintenance, showed promising results in patients with NSCLC, with reduced toxicity as compared with chemotherapy alone, but did not translate into longer overall survival.

Keywords: vascular endothelial growth factor, epidermal growth factor receptor, erlotinib, bevacizumab, non-small cell lung cancer

\section{Introduction}

The prognosis for patients with advanced non-small cell lung cancer (NSCLC) remains poor. While platinum-based combination chemotherapy has reached an efficacy plateau, preclinical and clinical data support the hypothesis that inhibiting multiple biological pathways that mediate tumor growth may be an effective therapeutic strategy. ${ }^{1}$ Progress in understanding cancer biology and mechanisms of oncogenesis has allowed the development of treatment against specific molecular targets, such as epidermal growth 
factor receptor (EGFR) and vascular endothelial growth factor (VEGF), which are of special interest in NSCLC.

Angiogenesis is considered to be an absolute prerequisite for malignant tumor growth and dissemination. ${ }^{2}$ VEGF is a key molecule in the upregulation of tumor angiogenesis. Targeting VEGF has led to major advances in treating different tumors. Bevacizumab, a recombinant humanized monoclonal antibody against VEGF, has shown relevant clinical activity in different types of human cancer, particularly in NSCLC. ${ }^{3}$ Two Phase III trials were designed for NSCLC patients with non-squamous cell tumors, comparing standard chemotherapy alone or treatment with bevacizumab. A survival benefit was demonstrated in the E4599 study and a benefit in progression-free survival in both studies for the combination arm. ${ }^{4,5}$

Activation of the EGFR pathway initiates a process that promotes tumor cell proliferation, angiogenesis, decreased apoptosis, and metastasis. ${ }^{6}$ EGFR has emerged as an attractive therapeutic target for patients with NSCLC. Erlotinib inhibits the tyrosine kinase activity of EGFR and has been studied extensively in randomized Phase III trials, ${ }^{7,8}$ yielding promising results, especially as second-line, third line, and maintenance therapy, and in patients with activating mutations of the EGFR receptor. ${ }^{9}$

Because tumor progression, metastasis, and angiogenesis depend on activation of multiple growth factor pathways and genetic alterations, ${ }^{10}$ it has been suggested that simultaneous blockade of several signaling pathways may improve treatment efficacy. This is the rationale for the combination of bevacizumab and erlotinib in NSCLC, which has proven to be well tolerated even when both are administered at their recommended Phase II dose. ${ }^{1}$ On this basis, a dual-center Phase I/II study was conducted to examine the combination of bevacizumab and erlotinib in patients with stage IIIb/IV or recurrent non-squamous NSCLC, with promising results. ${ }^{11}$ Another Phase II trial evaluated the safety of combining bevacizumab with either chemotherapy or erlotinib versus chemotherapy alone, and results for progression-free survival and overall survival favored the combination of bevacizumab with either chemotherapy or erlotinib over chemotherapy alone in the second-line setting. ${ }^{12}$ In contrast, more recently, the BeTa (Bevacizumab/Tarceva) trial, investigating the benefits of addition of bevacizumab to erlotinib for second-line treatment of advanced NSCLC, showed a doubling of progression-free survival with combination therapy (3.4 months) as compared with erlotinib monotherapy $(1.7$ months, $P<0.001)$ but no benefit in terms of overall survival. ${ }^{13}$ In this trial, we aimed to compare each targeted therapy alone (bevacizumab, erlotinib) with their combination and cytotoxic chemotherapy alone in previously untreated and advanced non-squamous NSCLC, following by administration of these agents as maintenance therapy. Moreover, in this study, we evaluated the role of radiological response of patients to the initial chemotherapy as a predictive factor, although this was not taken into consideration for the division of patients in subgroups.

\section{Materials and methods}

For this study, we enrolled patients with histologically or cytologically confirmed newly diagnosed stage IIIb or stage IV non-squamous NSCLC. Other inclusion criteria were age $\geq 18$ years, an Eastern Cooperative Oncology Group performance status of 0 or 1 , and adequate hematologic, hepatic, and renal function (including urinary excretion of $\leq 500 \mathrm{mg}$ of protein per day). Exclusion criteria included hemoptysis, a history of documented hemorrhagic diathesis or coagulopathy, therapeutic anticoagulation, radiation therapy within 21 days before enrolment or major surgery within 28 days before enrolment, clinically significant cardiovascular disease, medically uncontrolled hypertension, prior systemic chemotherapy for NSCLC, and symptomatic or untreated brain metastases. Patients with tumors invading or abutting major blood vessels (based on radiologist assessment) were also excluded.

\section{Study design}

Patients were randomly allocated to receive docetaxel and carboplatin chemotherapy alone (control group), bevacizumab in combination with chemotherapy (docetaxel and carboplatin chemotherapy + bevacizumab [bevacizumab group]), erlotinib in combination with chemotherapy (docetaxel and carboplatin chemotherapy + erlotinib [erlotinib group]), or bevacizumab in combination with erlotinib and chemotherapy (docetaxel and carboplatin chemotherapy + bevacizumab + erlotinib [combination group]). Randomization of this prospective four-arm study was performed with an allocation rate of 1:1:1:1 (Figure 1). It was an open-label study, without placebo, bevacizumab, or erlotinib used alone.

All patients initially received two cycles of chemotherapy with docetaxel $100 \mathrm{mg} / \mathrm{m}^{2}$ and carboplatin at a dose of area under the concentration-time curve of 5.5 every 28 days, ${ }^{14,15}$ and after laboratory assessment, were randomized into four groups. The first group (controls) received a further four cycles of docetaxel-carboplatin and continued with observation until disease progression. The second group (erlotinib) received four cycles of docetaxel-carboplatin plus 


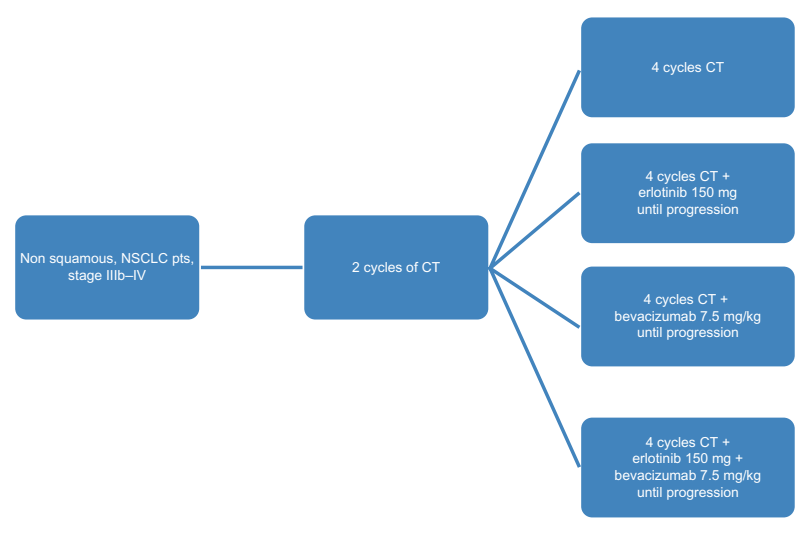

Figure I Study design.

Abbreviations: CT, chemotherapy; NSCLC, non-small cell lung cancer.

erlotinib administered orally at $150 \mathrm{mg} / \mathrm{dL}$ per day beginning on the first day of the third cycle and continued with erlotinib monotherapy thereafter until progression. The third group (bevacizumab) received four cycles of docetaxel-carboplatin plus bevacizumab $7.5 \mathrm{mg} / \mathrm{kg}$ by intravenous infusion every 28 days and continued with bevacizumab every 21 days until disease progression. The fourth group (combination therapy) received four cycles of chemotherapy plus bevacizumab $7.5 \mathrm{mg} / \mathrm{kg}$ every 28 days and erlotinib $150 \mathrm{mg} / \mathrm{dL}$, and continued with bevacizumab every 21 days and erlotinib until disease progression.

After the first two cycles of chemotherapy, patients who experienced progression of the disease to greater than $20 \%-25 \%$ of the initial dimensions of the tumor were not randomized. Patients who had progression to less than $20 \%-25 \%$ in the initial assessment were randomized and re-evaluated clinically and with a chest X-ray in the fourth cycle. If further deterioration of the disease was suspected and confirmed by computed tomography, patients were discontinued (three in the control group, four in the erlotinib group, none in the bevacizumab group, and one in the combination group), but they were included in the final statistical analysis for overall survival.

The second group received erlotinib with chemotherapy, although this combination has not demonstrated survival benefit compared with chemotherapy given alone, ${ }^{8}$ because when the study was designed, monotherapy with erlotinib had approval only as second-line therapy. The primary endpoint was overall survival. Secondary endpoints included improvement in time to progression, objective response rate, initial response rate to chemotherapy in chemonaïve patients, safety, and assessment of associations between efficacy endpoints and expression of EGFR and VEGF in tissue and plasma. All patients provided their informed consent before starting chemotherapy. The study protocol was approved by the ethical committee at our hospital and the scientific medical council of the Aristotle University of Thessaloniki.

\section{Laboratory correlates}

Plasma VEGF and EGFR levels were measured at baseline and before the third and sixth cycle of treatment in all patients using an enzyme-linked immunosorbent assay. EGFR and VEGF protein expression in lung cancer tissue was determined by immunohistochemical staining analysis of unstained slides, if available (using the DakoCytomation PharmDx test kit, DakoCytomation, Carpinteria, CA). Immunoreactivity was graded as positive if more than $10 \%$ of carcinoma cells were stained and negative if less than $10 \%$ were stained. ${ }^{16}$

\section{Tumor response}

Tumor response was determined by RECIST (Response Evaluation Criteria in Solid Tumors) version 1.0 criteria. ${ }^{17}$ Tumor assessment by computed tomography was performed at baseline and on day 28 of chemotherapy cycles 2 and 6 , and every 12 weeks following completion of chemotherapy. Chest X-ray, hematologic, renal, and hepatic function, and urine analysis were performed on day 28 of each cycle.

\section{Adverse events}

Adverse events were graded according to the US National Cancer Institute Common Toxicity Criteria for Adverse Events version 3.0. Patients were assessed for all grades of adverse events, serious adverse events, and adverse events requiring interruption or discontinuation of the study drug. For grade 1 or 2 toxic effects (diarrhea and rash occurred more frequently in the bevacizumab and combination groups), symptomatic treatment was recommended without reduction of the dose of erlotinib. For grade 3 toxic effects, a dose reduction (erlotinib $100 \mathrm{mg}$ ) or temporary interruption of therapy was needed. There was also special concern about pulmonary hemorrhage or any serious bleeding event (grade 3 or higher), especially in patients on bevacizumab and on the combination therapy.

\section{Statistical analysis}

Data are expressed as the median \pm standard error $(95 \%$ confidence interval $[\mathrm{CI}])$. The null hypothesis was rejected for an $\alpha$ level $<0.05$. Survival rates were calculated using the Kaplan-Meier method, and survival curves were compared using the log-rank test. All calculations involved two-sided $P$ values with an $\alpha=0.05$ and $80 \%$ power $(r=0.3$ medium effect size) and a 100-day survival benefit, according to the 
G*Power 3 test. ${ }^{18}$ We used stratified Cox proportional hazard models to estimate the hazard ratio (HR) and 95\% CI for overall survival and time to progression.

\section{Results}

Between May 2007 and December 2010, 229 patients were randomly assigned at our medical center. The first patient was enrolled on May 1, 2007 and the last patient on December 20, 2010. Sixty-one patients were assigned to the control group, 52 to the docetaxel and carboplatin chemotherapy + erlotinib group, 56 were assigned to the docetaxel and carboplatin chemotherapy + bevacizumab group, and 60 were assigned to docetaxel and carboplatin chemotherapy + bevacizumab + erlotinib group. The median follow-up duration was $440 \pm 51.20$ days (95\% CI 341-545). Table 1 shows selected demographic and baseline characteristics for all patients randomized, and Figure 2 shows a consort diagram for the eligible patients.

\section{Efficacy analysis}

Overall survival did not differ between patients in the four groups $(P=0.381)$. Median duration of overall survival was longer in the combination group than in the other groups, although not statistically significant (Figure 3).
Pairwise comparisons did not reveal any statistically significant difference between the four study arms. Median overall survival was 460 days (95\% CI 270-650) in the control group, 491 (95\% CI 290-692) in the erlotinib group, 574 (95\% CI 378-769) in the bevacizumab group, and 663 (95\% CI 370-955) in the combination group (Table 2).

By Kaplan-Meier analysis, one-year survival was $16 \%$ in the control group, $27 \%$ in the erlotinib group, $39 \%$ in the bevacizumab group, and $18 \%$ in the combination group. Based on observation of the Kaplan-Meier curves, a statistical analysis in the first 450 days (15 months) of the study was performed and showed that the bevacizumab group had a survival benefit compared with the other groups, ie, 248 (190-305) days for the control group, 299 (229-368) days for the erlotinib group, 380 (317-442) for the bevacizumab group, and 284 (275-292) for the combination group $(P=0.023$, Figure 4).

Time to progression did not differ significantly between the four groups at the end of the study, but time to progression of the disease was significantly longer in the combination group at the end of the first year of the study $(P=0.001$, Table 3).

Table 4 shows an analysis of objective response rate, which was greater in the groups receiving targeted therapies

Table I Patient characteristics

\begin{tabular}{|c|c|c|c|c|c|c|c|c|}
\hline & \multicolumn{2}{|c|}{$\begin{array}{l}\text { Control group } \\
(n=6 I)\end{array}$} & \multicolumn{2}{|c|}{$\begin{array}{l}\text { Erlotinib group } \\
(n=52)\end{array}$} & \multicolumn{2}{|c|}{$\begin{array}{l}\text { Bevacizumab group } \\
(n=56)\end{array}$} & \multicolumn{2}{|c|}{$\begin{array}{l}\text { Combination group } \\
(n=60)\end{array}$} \\
\hline & $\mathrm{n}$ & $\%$ & $n$ & $\%$ & $\mathrm{n}$ & $\%$ & $n$ & $\%$ \\
\hline \multicolumn{9}{|l|}{ Age (years) } \\
\hline Median & 65 & & 62.5 & & 62.5 & & 60 & \\
\hline$>65$ & 25 & 41 & 17 & $33 \%$ & 22 & 39 & 20 & 33 \\
\hline$\leq 65$ & 36 & 59 & 35 & $67 \%$ & 34 & 61 & 40 & 67 \\
\hline \multicolumn{9}{|l|}{ Gender } \\
\hline Male & 52 & 85 & 40 & $77 \%$ & 45 & 80 & 50 & 83 \\
\hline Female & 4 & 15 & 12 & $23 \%$ & 11 & 20 & 10 & 17 \\
\hline \multicolumn{9}{|l|}{ Disease stage } \\
\hline IIlb & 10 & 16 & 13 & $25 \%$ & 15 & 27 & 10 & 17 \\
\hline IV & 51 & 84 & 39 & $75 \%$ & 41 & 73 & 50 & 83 \\
\hline \multicolumn{9}{|l|}{ Histologic type } \\
\hline Adenocarcinoma & 56 & 92 & 48 & 92 & 50 & 89 & 52 & 87 \\
\hline Large cell & 5 & 8 & 4 & 8 & 6 & II & 8 & 13 \\
\hline \multicolumn{9}{|l|}{ Smoking history } \\
\hline Never & 8 & 13 & 8 & 15 & 9 & 16 & 2 & 3 \\
\hline Previous & 39 & 64 & 39 & 75 & 45 & 80 & 53 & 88 \\
\hline Current & 14 & 23 & 5 & 10 & 2 & 4 & 5 & 8 \\
\hline \multicolumn{9}{|l|}{ EGFR status } \\
\hline $\mathrm{IHC}(+)$ & $26 / 40$ & 65 & $22 / 30$ & 73 & $7 / 32$ & 22 & $12 / 30$ & 40 \\
\hline $\operatorname{IHC}(-)$ & $14 / 40$ & 35 & $8 / 30$ & 27 & $25 / 32$ & 73 & $18 / 30$ & 60 \\
\hline \multicolumn{9}{|l|}{ VEGF status } \\
\hline $\mathrm{IHC}(+)$ & $24 / 40$ & 60 & $11 / 30$ & 37 & $10 / 32$ & 31 & $16 / 30$ & 53 \\
\hline IHC (-) & $16 / 40$ & 40 & $19 / 30$ & 63 & $22 / 32$ & 69 & $14 / 30$ & 47 \\
\hline
\end{tabular}

Abbreviations: EGFR, epidermal growth factor receptor; IHC, immunohistochemistry; VEGF, vascular endothelial growth factor. 


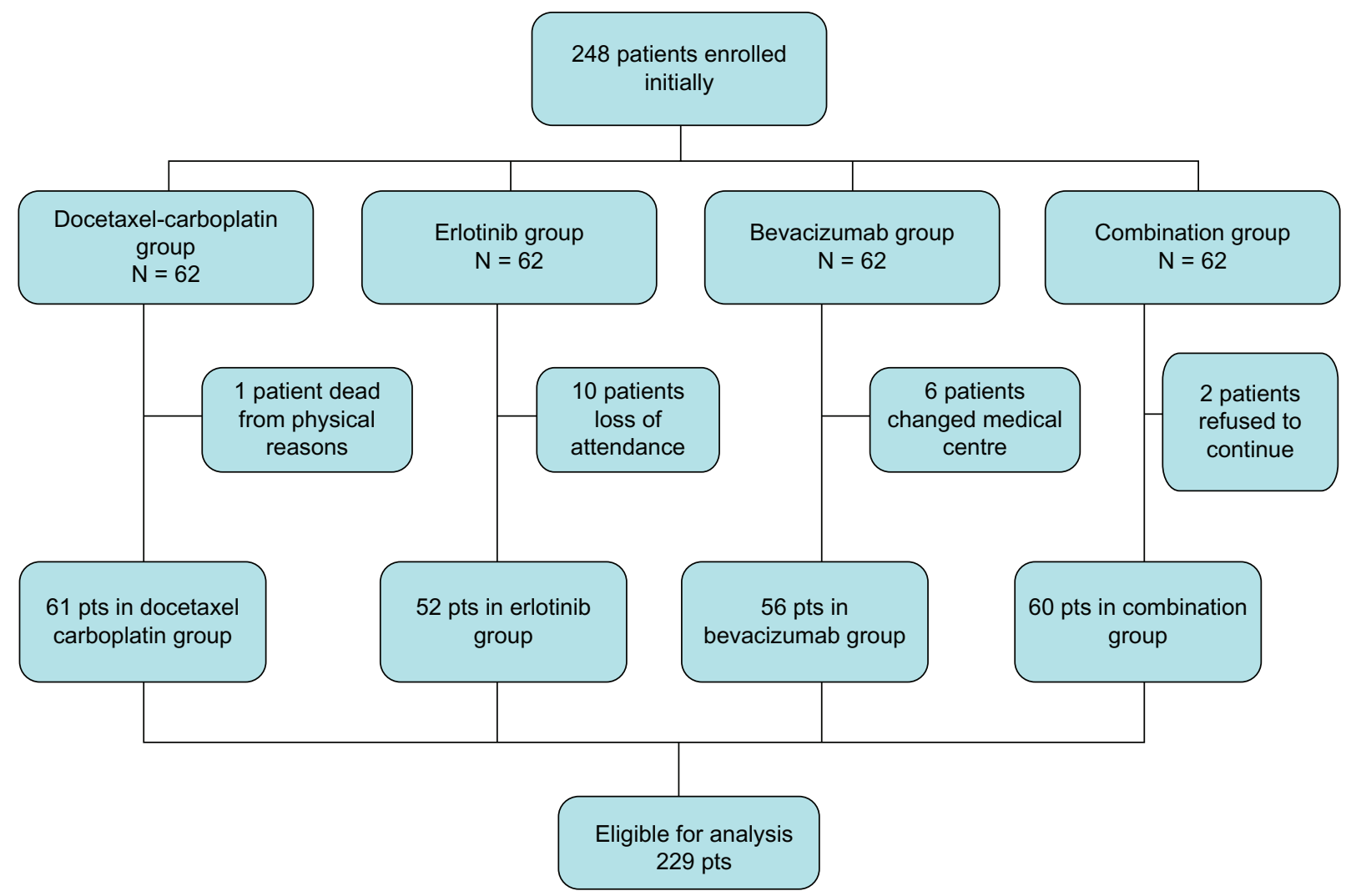

Figure 2 Consort diagram. 248 patients were enrolled. The patients received firstly 2 cycles of chemotherapy (docetaxel plus carboplatin) and then they were randomly divided into four groups. In total 229 patients were eligible for data analysis.

than in the control group. When the patients were divided into responders (those with a complete, partial, or minor response, or stable disease) and nonresponders (those with progressive disease) according to their response in the initial assessment, it was evident that patients who did not respond to the initial two cycles of cytotoxic chemotherapy do not respond at all to chemotherapy overall (Table 5).

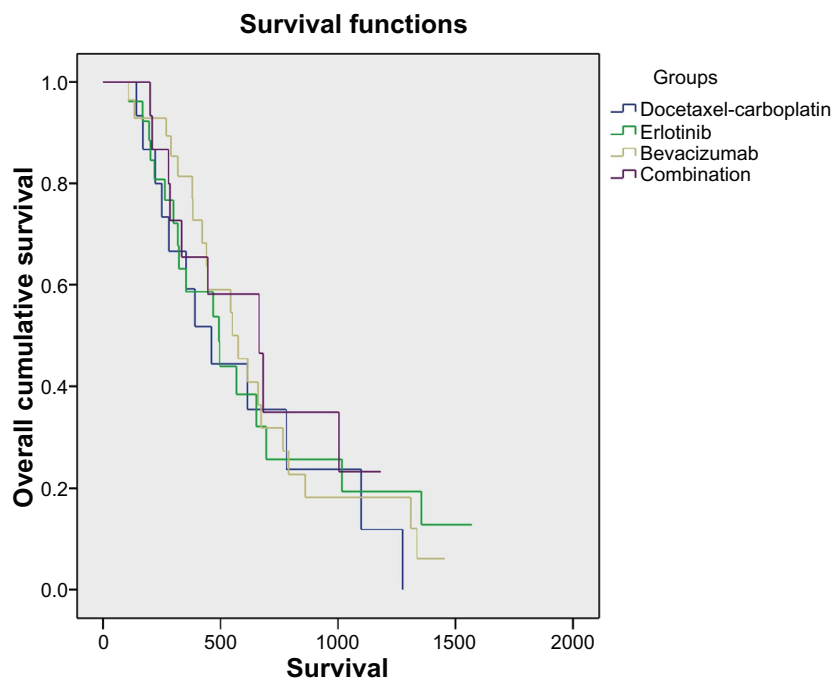

Figure 3 Kaplan-Meier curve for overall survival.
After two cycles of chemotherapy, nonresponders who received additional treatment with bevacizumab or combination therapy had a survival benefit [657 (349-970) days and 681 (315-912) days, respectively], which was statistically significant compared with the continuation of treatment with cytotoxic chemotherapy $(P<0.001)$. Moreover, this survival benefit in nonresponders with the addition of bevacizumab to cytotoxic docetaxel and carboplatin chemotherapy continued after six cycles of docetaxel and carboplatin chemotherapy and after 3 months of maintenance therapy with bevacizumab (Table 5).

One hundred and thirty-two (57\%) of the 229 patients enrolled had tumor tissue available for EGFR and VEGF immunohistochemistry. Further, 183 patients had results for serum EGFR and VEGF levels. VEGF and EGFR expression in tumor tissue in general had no correlation with survival

Table 2 Median overall survival in the four treatment groups

\begin{tabular}{lllll}
\hline & $\mathbf{C T}$ & $\mathbf{C T}+\mathbf{E}$ & $\mathbf{C T}+\mathbf{B}$ & $\mathbf{C T}+\mathbf{B}+\mathbf{E}$ \\
\hline Median OS & 460 days & $49 \mathrm{I}$ days & 574 days & 663 days \\
HR & - & 0.809 & 0.768 & 0.655 \\
$95 \%$ Cl for HR & - & $0.39-1.7$ & $0.38-1.6$ & $0.27-1.5$ \\
\hline
\end{tabular}

Abbreviations: $\mathrm{B}$, bevacizumab; $\mathrm{Cl}$, confidence interval; $\mathrm{CT}$, docetaxel and carboplatin chemotherapy; E, erlotinib; HR, hazard ratio. 


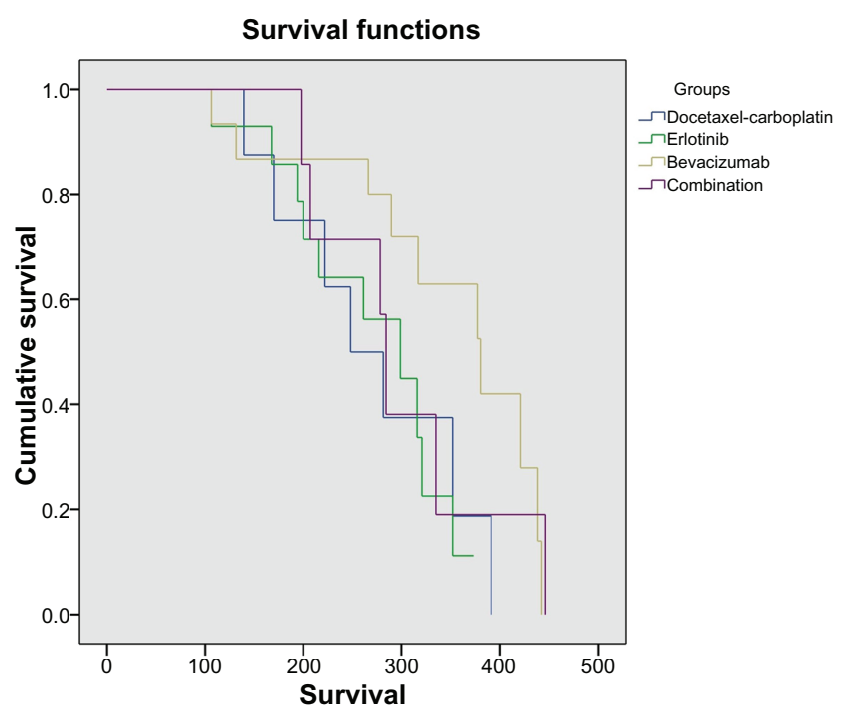

Figure 4 Kaplan-Meier curves for cumulative survival at 15 months.

( $P=0.18$ and $P=0.19$, respectively). Nevertheless, if we compare patients according to their treatment allocation, a statistically significant survival benefit is observed in patients who received erlotinib or bevacizumab and expressed VEGF $(P=0.002$ and $P=0.013$, respectively), while patients receiving cytotoxic chemotherapy had a survival benefit compared with the other groups $(P=0.034)$ when VEGF and EGFR were not expressed in tumor tissue (Table 6, Figures 5 and 6). Serum VEGF and EGFR levels before and after treatment did not correlate with overall survival rate $(P=0.15)$.

\section{EGFR mutations and prognosis in NSCLC}

A subgroup analysis of patients with longer survival ( $>1.5$ years) was performed. In 24 patients for whom tumor tissue was available for determination of EFGR mutation status, we investigated the sequence of the gene encoding a tyrosine kinase region (exons 18-21). These mutations

Table 3 Time to progression among the four treatment groups

\begin{tabular}{|c|c|c|}
\hline & $\begin{array}{l}\text { TTP in year } 2 \\
n=184 \\
P=0.00 I\end{array}$ & $\begin{array}{l}\text { TTP in year } 2 \\
n=125 \\
P=0.27\end{array}$ \\
\hline $\begin{array}{l}\text { Control } \\
\text { group }\end{array}$ & $\begin{array}{l}67 \text { days }(95 \% \mathrm{Cl} 35-96) \\
(\mathrm{n}=49 / 184)\end{array}$ & $\begin{array}{l}82 \text { days }(95 \% \mathrm{Cl} 30-132) \\
(\mathrm{n}=32 / 125)\end{array}$ \\
\hline $\begin{array}{l}\text { Erlotinib } \\
\text { group }\end{array}$ & $\begin{array}{l}\text { I } 80 \text { days }(95 \% \mathrm{Cl} 70-289) \\
(\mathrm{n}=50 / / 84)\end{array}$ & $\begin{array}{l}\text { I } 80(95 \% \mathrm{Cl} \mid \mathrm{I} \text { | }-244) \\
(\mathrm{n}=40 / \mathrm{I} 25)\end{array}$ \\
\hline $\begin{array}{l}\text { Bevacizumab } \\
\text { group }\end{array}$ & $\begin{array}{l}\text { I8I days }(95 \% \mathrm{Cl} 68-295) \\
(\mathrm{n}=55 / / 84)\end{array}$ & $\begin{array}{l}\mathrm{I} 74 \text { days }(95 \% \mathrm{Cl}|66-| 8 \mid) \\
(\mathrm{n}=36 / \mathrm{I} 25)\end{array}$ \\
\hline $\begin{array}{l}\text { Combination } \\
\text { group }\end{array}$ & $\begin{array}{l}218 \text { days }(95 \% \mathrm{Cl} 195-240) \\
(\mathrm{n}=24 / 184)\end{array}$ & $\begin{array}{l}\text { I } 98 \text { days }(95 \% \mathrm{Cl} \mid 46-250) \\
(\mathrm{n}=|\mathrm{I} /| \mathrm{I} 25)\end{array}$ \\
\hline
\end{tabular}

Abbreviation: TTP, time to progression.
Table 4 Analysis of objective response rate

\begin{tabular}{|c|c|c|c|c|}
\hline & CT & $C T+E$ & $C T+B$ & $C T+E+B$ \\
\hline $\begin{array}{l}\text { Response before } \\
\text { randomization }\end{array}$ & $\mathrm{n}=6 \mathrm{I}$ & $\mathrm{n}=52$ & $\mathrm{n}=56$ & $\mathrm{n}=60$ \\
\hline PD & $10(17 \%)$ & $8(15 \%)$ & $9(16 \%)$ & $8(13 \%)$ \\
\hline SD & $19(26 \%)$ & $20(38 \%)$ & $12(21 \%)$ & $12(19 \%)$ \\
\hline$M R$ & $20(33 \%)$ & 22 (42\%) & 18 (32\%) & $24(38 \%)$ \\
\hline PR & $12(20 \%)$ & $5(10 \%)$ & $15(27 \%)$ & $16(25 \%)$ \\
\hline Response after & $\mathrm{n}=58$ & $\mathrm{n}=48$ & $\mathrm{n}=56$ & $\mathrm{n}=59$ \\
\hline \multicolumn{5}{|l|}{6 cycles of CT } \\
\hline PD & $24(43 \%)$ & $10(21 \%)$ & $8(14 \%)$ & $4(6 \%)$ \\
\hline SD & $16(28 \%)$ & 15 (31\%) & $26(46 \%)$ & 32 (54\%) \\
\hline$M R$ & 12 (2।\%) & $10(21 \%)$ & $9(16 \%)$ & 14 (23\%) \\
\hline PR & $6(11 \%)$ & $12(25 \%)$ & $13(23 \%)$ & $12(20 \%)$ \\
\hline CR & & I (2\%) & & \\
\hline Objective response & 18 (31\%) & $23(48 \%)$ & $22(39 \%)$ & $26(44 \%)$ \\
\hline Disease control rate & $34(58 \%)$ & $38(78 \%)$ & $48(86 \%)$ & 29 (98\%) \\
\hline Response after & $\mathrm{n}=44$ & $n=4 I$ & $\mathrm{n}=44$ & $\mathrm{n}=5 \mathrm{l}$ \\
\hline \multicolumn{5}{|l|}{$\begin{array}{l}3 \text { months of } \\
\text { completion of CT }\end{array}$} \\
\hline PD & $32(72 \%)$ & 14 (34\%) & $12(27 \%)$ & $16(31 \%)$ \\
\hline SD & $12(27 \%)$ & $18(44 \%)$ & $20(45 \%)$ & 24 (47\%) \\
\hline$M R$ & & $3(7 \%)$ & $7(16 \%)$ & $12(23 \%)$ \\
\hline PR & & $6(15 \%)$ & $3(7 \%)$ & $2(7 \%)$ \\
\hline CR & & & $2(5 \%)$ & \\
\hline Objective response & & $9(22 \%)$ & $12(27 \%)$ & $16(31 \%)$ \\
\hline Disease control rate & $12(27 \%)$ & $27(66 \%)$ & 32 (73\%) & 40 (77\%) \\
\hline
\end{tabular}

Abbreviations: B, bevacizumab; $\mathrm{CT}$, docetaxel and carboplatin chemotherapy; $\mathrm{E}$, erlotinib; $\mathrm{PD}$, progressive disease; $\mathrm{SD}$, stable disease; $\mathrm{MR}$, minimal response; $\mathrm{PR}$, partial response.

were detected using high resolution melting analysis and identified by direct determination of the DNA sequence (sequencing using ABI Prism 3130 sequencer) in the exons. Of 24 patients, six had EGFR-mutated tumors. Although subgroup analysis of overall survival seemed to favor patients with EGFR-mutated tumors compared with wild-type EGFR tumors, the difference did not reach statistical significance $(P=0.134$, Figure 7$)$.

\section{Adverse events}

The adverse event rate was similar in the four treatment groups. Twenty-eight (47\%) of the 61 patients in the control group experienced adverse hematological events, ten (17\%) of which were grade 3 or 4 , compared with seven (13\%) of the 52 patients in the erlotinib group, ten (18\%) of the 56 patients in the bevacizumab group, and $18(28 \%)$ of the 60 patients in the combination group (Table 7). The incidence of grade 3 arterial thromboembolic events (pulmonary embolism) was higher in the bevacizumab group than in the other groups, but was much lower than the rates previously reported in patients with advanced NSCLC and treated with bevacizumab. ${ }^{4}$ Two patients (4\%) in the bevacizumab group 
Table 5 Patients with progressive disease (nonresponders)

\begin{tabular}{|c|c|c|c|}
\hline \multirow{2}{*}{$\begin{array}{l}\text { Patients with progressive } \\
\text { disease (nonresponders) }\end{array}$} & \multicolumn{3}{|l|}{ Survival in days } \\
\hline & After 2 cycles of CT & After 6 cycles of CT & $\begin{array}{l}\text { After } 3 \text { months of } \\
\text { maintenance therapy }\end{array}$ \\
\hline$\overline{C T}$ & 170 & 248 & 314 \\
\hline $\mathrm{CT}+\mathrm{E}$ & 168 & 261 & 299 \\
\hline $\mathrm{CT}+\mathrm{B}$ & 657 & 316 & 541 \\
\hline \multirow[t]{2}{*}{$C T+B+E$} & 681 & 438 & 284 \\
\hline & $P<0.001$ & $P=0.017$ & $P=0.011$ \\
\hline
\end{tabular}

Abbreviations: B, bevacizumab; $\mathrm{CT}$, docetaxel and carboplatin chemotherapy; E, erlotinib.

and two $(3 \%)$ in the combination group had grade 3 or 4 hypertension (Table 7).

Three patients $(5 \%)$ in the control group discontinued treatment because of adverse events compared with four $(8 \%)$ in the erlotinib group, two (4\%) in the bevacizumab group, and six (9\%) in the combination group. After discontinuation of treatment, patients received palliative therapy, second/ third-line chemotherapy, or radiotherapy, as necessary.

\section{Discussion}

Dual inhibition reduces tumor endothelial proliferation compared with VEGF or EGFR blockade alone. ${ }^{19}$ However, our trial did not find a statistically significant advantage in favor of the combination of bevacizumab and erlotinib, as did the recent BeTa trial, ${ }^{13}$ although the combination group had a survival benefit of 200 days (6.5 months) compared with the control group, albeit not statistically significant.

Moreover, the combination of bevacizumab and erlotinib delayed disease progression until the end of the first year of treatment. A synergistic role of inhibition of angiogenesis and tumor growth might account for the delay in disease progression, with development of resistance by tumor cells rendering the targeted agents inactive after a period of time..$^{20}$

The response to the second cycle of chemotherapy can predict overall response in patients with NSCLC. ${ }^{18}$ Dividing patients into responders and nonresponders according to

Table 6 VEGF and EGFR in tissue and survival in days

\begin{tabular}{|c|c|c|c|c|}
\hline & \multicolumn{2}{|l|}{ VEGF } & \multicolumn{2}{|l|}{ EGFR } \\
\hline & IHC (-) & IHC (+) & IHC (-) & IHC (+) \\
\hline \multicolumn{5}{|c|}{ Survival in days } \\
\hline $\mathrm{CT}$ & 1098 & 222 & 1277 & 391 \\
\hline $\mathrm{CT}+\mathrm{E}$ & 467 & 694 & 467 & 495 \\
\hline$C T+B$ & 657 & 1310 & 438 & 765 \\
\hline \multirow[t]{2}{*}{$C T+B+E$} & 284 & 278 & 207 & 284 \\
\hline & $P=0.034$ & $P<0.001$ & $P=0.031$ & $P=0.035$ \\
\hline
\end{tabular}

Abbreviations: B, bevacizumab; CT, docetaxel and carboplatin chemotherapy; E, erlotinib; EGFR, epidermal growth factor receptor; IHC, immunohistochemistry; VEGF, vascular endothelial growth factor. their response at initial assessment, nonresponders to initial cytotoxic chemotherapy did not respond to the next cycles of the same initial regimens. ${ }^{21}$

Another issue in patients with NSCLC is the optimal treatment duration. Large studies, including AVAIL (Avastin in Lung) and ATLAS (A Study Comparing Bevacizumab Therapy With or Without Erlotinib for First-Line Treatment of Non-Small Cell Lung Cancer), ${ }^{5,22}$ confirmed the efficacy of bevacizumab as maintenance therapy and demonstrated that the benefit is further improved by addition of erlotinib. During the first year of treatment, bevacizumab combined with chemotherapy seemed to confer a significant survival benefit compared with the other treatment groups.

In our study, patients with progressive disease who did not respond to initial chemotherapy survived for longer when they received bevacizumab, not only as initial treatment, but also as maintenance therapy for more than six cycles. Further, better response rates were achieved in the groups receiving targeted therapies ( $0 \%$ for the control group, $22 \%$ for the erlotinib group, $27 \%$ for the bevacizumab group, and

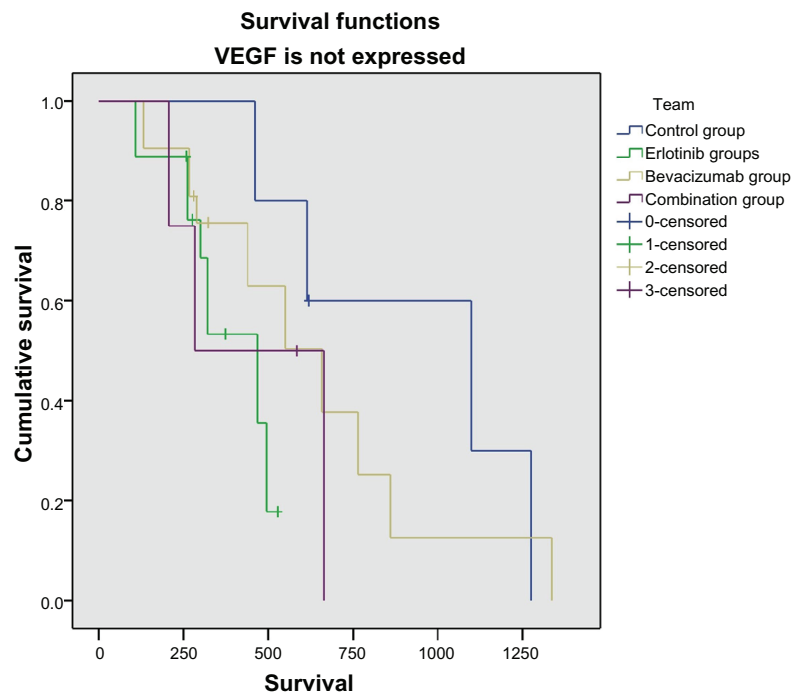

Figure 5 Kaplan-Meier curve for survival without vascular endothelial growth factor expression.

Abbreviation: VEGF, vascular endothelial growth factor. 


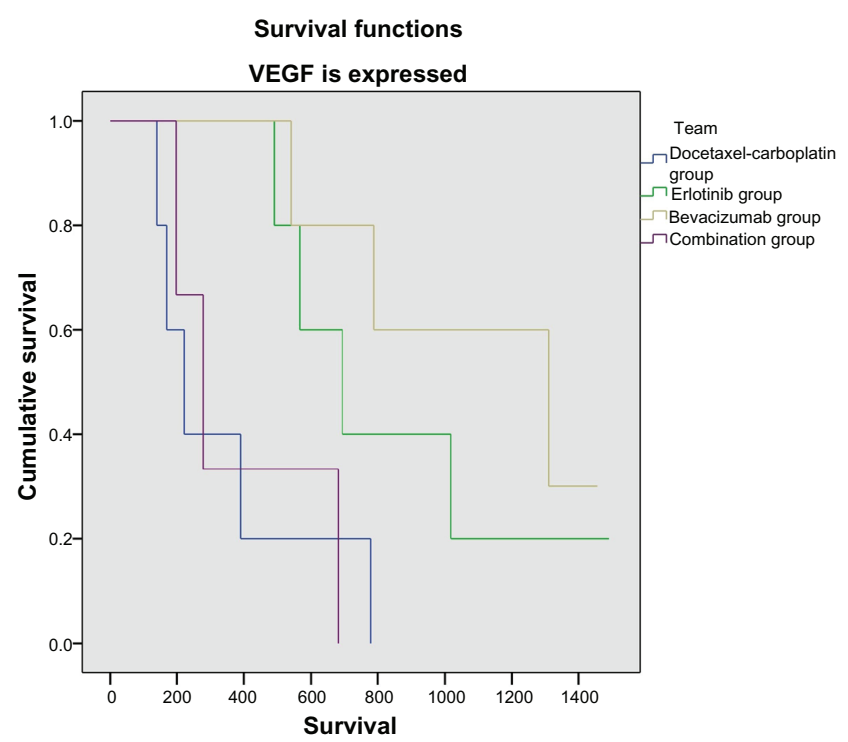

Figure 6 Kaplan-Meier curve for survival, with vascular endothelial growth factor expression.

Abbreviation: VEGF, vascular endothelial growth factor.

$30 \%$ for the combination group, after 3 months of cytotoxic chemotherapy and continuation with targeted agents).

The targeted therapies had an acceptable safety profile, despite being combined with cytotoxic chemotherapy, probably because of the low dose of bevacizumab used $(7.5 \mathrm{mg} / \mathrm{kg})$. The importance of identifying molecular prognostic factors has been emphasized with the development of targeted treatment, but for NSCLC the field remains open as

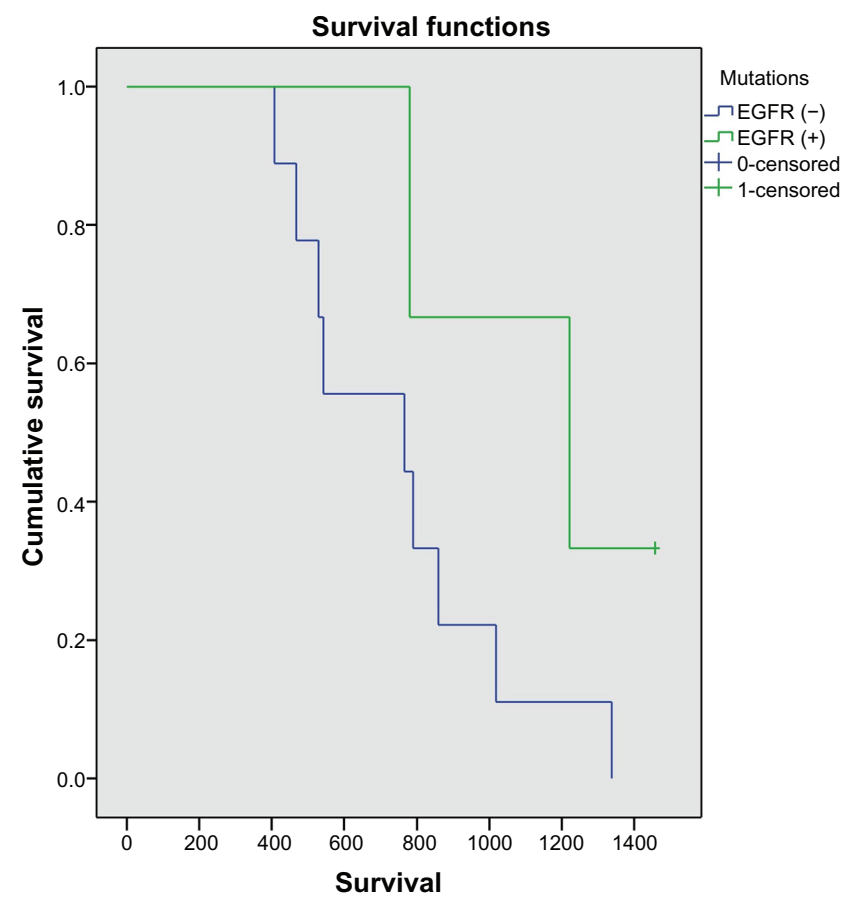

Figure 7 Kaplan-Meier curve for overall survival and epithelial growth factor receptor mutations.

Abbreviations: EGFR (-), negative expression; EGFR (+), positive expression. a result of the large volume of conflicting data, especially for bevacizumab. ${ }^{23}$ In our study, expression of VEGF and EGFR in tumor tissue in general had no correlation with survival. Nevertheless, patients who expressed VEGF and received erlotinib or bevacizumab had a statistically significant survival benefit compared with the control group, perhaps because of blockade of VEGF.

Expression, overexpression, and mutation of EGFR have been implicated in the pathogenesis of NSCLC, ${ }^{24}$ suggesting that patients with EGFR mutations might derive increased benefit from EGFR-targeted therapies. ${ }^{25}$ In our study, although subgroup analysis suggested that overall survival was better in patients with EGFR-mutated tumors compared with wild-type EGFR tumors, the difference did not achieve statistical significance. However, this result should be interpreted with caution because examination of EGFR mutation in cancer tissue was performed retrospectively in patients with prolonged survival, and the patient population in our study was quite small.

The main limitation of our study is that, when the protocol was designed, erlotinib was not approved for first-line therapy as a single agent, and this is why we administered erlotinib in combination with chemotherapy. Another limitation of the study was the lack of data for VEGF and EGFR expression in lung cancer tissue in all patients enrolled in the study, some of whom were diagnosed cytologically. Further, for financial reasons, determination of EGFR mutation was performed retrospectively and not in all patients. It should be noted that the survival benefit was statistically significant in the bevacizumab group at the 450-day survival analysis, and this was an ad hoc result based on initial observation of the Kaplan-Meier curve. Another limitation is the need for prolonged (more than 2 years) follow-up, especially in patients with long-term survival and positive expression of VEGF. It would be interesting in the future to compare other targeting agents administered alone or in combination with traditional chemotherapy in NSCLC patients who are nonresponders.

Despite improvements in several efficacy endpoints, improving survival remains a challenge in the treatment of NSCLC. This randomized study suggests that bevacizumab enhances the activity of chemotherapy, mainly in patients who do not respond to initial cytotoxic chemotherapy. Taking into account the cost of biological agents, we could use initial response as a predictor of whether to add bevacizumab to standard chemotherapy for the treatment of NSCLC. Combination of erlotinib and bevacizumab did 
Table 7 Adverse events

\begin{tabular}{|c|c|c|c|c|c|c|c|c|}
\hline \multirow[t]{2}{*}{ Adverse events } & \multicolumn{2}{|l|}{$\begin{array}{l}\text { CT } \\
n=6 I\end{array}$} & \multicolumn{2}{|l|}{$\begin{array}{l}C T+E \\
n=52\end{array}$} & \multicolumn{2}{|l|}{$\begin{array}{l}C T+B \\
n=56\end{array}$} & \multicolumn{2}{|l|}{$\begin{array}{l}C T+B+E \\
n=60\end{array}$} \\
\hline & Grade 3/4 & All grades & Grade $3 / 4$ & All grades & Grade $3 / 4$ & All grades & Grade 3/4 & All grades \\
\hline Anemia & 4 & 10 & I & 2 & I & 3 & 4 & 8 \\
\hline Neutropenia & 6 & 14 & I & 3 & 2 & 3 & 2 & 6 \\
\hline Thrombocytopenia & 0 & 4 & 0 & 2 & 3 & 4 & 2 & 4 \\
\hline Hypertension & 0 & 0 & 0 & 0 & 2 & 3 & 2 & 2 \\
\hline Rash & 0 & 0 & 5 & 7 & 0 & 0 & 8 & 12 \\
\hline Diarrhea & 0 & 0 & 2 & 4 & 0 & 0 & 4 & 8 \\
\hline Hemoptysis & 0 & 0 & 0 & 0 & I & 2 & 2 & 5 \\
\hline Proteinuria & 0 & 0 & 0 & 0 & I & 4 & 0 & 4 \\
\hline Renal failure & 3 & 5 & 0 & 0 & 0 & 0 & 0 & 0 \\
\hline Cardiotoxicity & 2 & 2 & 0 & 0 & 0 & 0 & 0 & 0 \\
\hline Pulmonary embolism & 0 & 0 & 0 & 0 & I & I & 0 & 0 \\
\hline
\end{tabular}

Abbreviations: CT, chemotherapy; E, erlotinib; B, bevasizumab.

not prolong overall survival. Results from larger studies are eagerly awaited to help determine how these antiangiogenic agents may be best used either alone or in combination with traditional chemotherapy regimens. The advantages and disadvantages have to be presented along with the disadvantages of toxicity and cost effect.

\section{Disclosure}

The authors report no conflicts of interest in this work.

\section{References}

1. Jung YD, Mansfield PF, Akagi M, et al. Effects of combination antivascular endothelial growth factor receptor and anti-epidermal growth factor receptor therapies on the growth of gastric cancer in a nude mouse model. Eur J Cancer. 2002;38(8):1133-1140.

2. Kerbel RS. Tumor angiogenesis. N Engl J Med. 2008;358(19): 2039-2049.

3. Gridelli C, Maione P, Rossi A, De Marinis F. The role of bevacizumab in the treatment of non-small cell lung cancer: current indications and future developments. Oncologist. 2007;12(10):1183-1193.

4. Sandler A, Gray R, Perry MC, et al. Paclitaxel-carboplatin alone or with bevacizumab for non-small-cell lung cancer. $N$ Engl J Med. 2006;355(24):2542-2550.

5. Reck M, von Pawel J, Zatloukal P, et al. Phase III trial of cisplatin plus gemcitabine with either placebo or bevacizumab as first-line therapy for nonsquamous non-small-cell lung cancer: AVAIL. J Clin Oncol. 2009;27(8):1227-1234.

6. Arteaga C. Targeting HER1/EGFR: a molecular approach to cancer therapy. Semin Oncol. 2003;30(3 Suppl 7):3-14.

7. Shepherd FA, Rodrigues Pereira J, Ciuleanu T, et al. Erlotinib in previously treated non-small-cell lung cancer. N Engl J Med. 2005;353(2): 123-132.

8. Herbst RS, Prager D, Hermann R, et al. TRIBUTE: a phase III trial of erlotinib hydrochloride (OSI-774) combined with carboplatin and paclitaxel chemotherapy in advanced non-small-cell lung cancer. J Clin Oncol. 2005;23(25):5892-5899.

9. Cappuzzo F, Ciuleanu T, Stelmakh L, et al. Erlotinib as maintenance treatment in advanced non-small-cell lung cancer: a multicentre, randomised, placebo-controlled phase 3 study. Lancet Oncol. 2010; 11(6):521-529.

10. O'Reilly MS. Therapeutic strategies using inhibitors of angiogenesis. Methods Mol Biol. 2003;223:599-634.
11. Herbst RS, Johnson DH, Mininberg E, et al. Phase I/II trial evaluating the anti-vascular endothelial growth factor monoclonal antibody bevacizumab in combination with the HER-1/epidermal growth factor receptor tyrosine kinase inhibitor erlotinib for patients with recurrent non-small-cell lung cancer. J Clin Oncol. 2005;23(11):2544-2555.

12. Herbst RS, O'Neill VJ, Fehrenbacher L, et al. Phase II study of efficacy and safety of bevacizumab in combination with chemotherapy or erlotinib compared with chemotherapy alone for treatment of recurrent or refractory non small-cell lung cancer. J Clin Oncol. 2007;25(30):4743-4750.

13. Herbst RS, Ansari R, Bustin F, et al. Efficacy of bevacizumab plus erlotinib versus erlotinib alone in advanced non-small-cell lung cancer after failure of standard first-line chemotherapy (BeTa): a double-blind, placebo-controlled, phase 3 trial. Lancet. 2011;377(9780):1846-1854.

14. Millward MJ, Boyer MJ, Lehnert M, et al. Docetaxel and carboplatin is an active regimen in advanced non-small-cell lung cancer: a phase II study in Caucasian and Asian patients. Ann Oncol. 2003;14(3):449-454.

15. Zarogoulidis K, Kontakiotis T, Hatziapostolou P, et al. A Phase II study of docetaxel and carboplatin in the treatment of non-small cell lung cancer. Lung Cancer. 2001;32(3):281-287.

16. Cascinu S, Staccioli MP, Gasparini G, et al. Expression of vascular endothelial growth factor can predict event-free survival in stage II colon cancer. Clin Cancer Res. 2000;6(7):2803-2807.

17. Therasse P, Arbuck SG, Eisenhauer EA, et al. New guidelines to evaluate the response to treatment in solid tumors. European Organization for Research and Treatment of Cancer, National Cancer Institute of the United States, National Cancer Institute of Canada. J Natl Cancer Inst. 2000;92(3):205-216.

18. Faul F, Erdfelder E, Lang AG, Buchner A. G*Power 3: a flexible statistical power analysis program for the social, behavioral, and biomedical sciences. Behav Res Methods. 2007;39(2):175-191.

19. Naumov GN, Nilsson MB, Cascone T, et al. Combined vascular endothelial growth factor receptor and epidermal growth factor receptor (EGFR) blockade inhibits tumor growth in xenograft models of EGFR inhibitor resistance. Clin Cancer Res. 2009;15(10):3484-3494.

20. Sattler M, Abidoye O, Salgia R. EGFR-targeted therapeutics: focus on SCCHN and NSCLC. Scientific World Journal. 2008;8:909-919.

21. Hanna N, Shepherd FA, Fossella FV, et al. Randomized phase III trial of pemetrexed versus docetaxel in patients with non-small-cell lung cancer previously treated with chemotherapy. J Clin Oncol. 2004; 22(9):1589-1597.

22. Miller VA, O'Connor $P$, Soh C, et al; for the ATLAS Investigators. A randomized, double-blind, placebo-controlled, phase IIIb trial (ATLAS) comparing bevacizumab (B) therapy with or without erlotinib (E) after completion of chemotherapy with B for first-line treatment of locally advanced, recurrent, or metastatic non-small cell lung cancer (NSCLC) J Clin Oncol. 2009;27(Suppl 18):Abstr LBA8002. 
23. Timotheadou E, Skarlos DV, Samantas E, et al. Evaluation of the prognostic role of a panel of biomarkers in stage IB-IIIA non-small cell lung cancer patients. Anticancer Res. 2007;27(6C):4481-4489.

24. Pao W, Miller V, Zakowski M, et al. EGF receptor gene mutations are common in lung cancers from "never smokers" and are associated with sensitivity of tumors to gefitinib and erlotinib. Proc Natl Acad Sci U S A. 2004;101(36):13306-13311.
25. Reguart N, Cardona AF, Rosell R. Role of erlotinib in first-line and maintenance treatment of advanced non-small-cell lung cancer. Cancer Manag Res. 2010;2:143-156.

\section{Publish your work in this journal}

OncoTargets and Therapy is an international, peer-reviewed, open access journal focusing on the pathological basis of all cancers, potential targets for therapy and treatment protocols employed to improve the management of cancer patients. The journal also focuses on the impact of management programs and new therapeutic agents and protocols on

\section{Dovepress}

patient perspectives such as quality of life, adherence and satisfaction. The manuscript management system is completely online and includes a very quick and fair peer-review system, which is all easy to use. Visit http://www.dovepress.com/testimonials.php to read real quotes from published authors.

Submit your manuscript here: http://www.dovepress.com/oncotargets-and-therapy-journal 